OPEN ACCESS

Edited by:

Giovanna Suzzi

University of Teramo, Italy

Reviewed by:

Francisco José Pérez-Cano,

University of Barcelona, Spain

Chaoxin Man,

Northeast Agricultural University,

China

*Correspondence:

Guadalupe González-Ochoa

guadalupe.gonzalezochoa@unison.mx

Specialty section: This article was submitted to

Food Microbiology,

a section of the journal

Frontiers in Microbiology

Received: 05 March 2020

Accepted: 15 April 2020

Published: 12 May 2020

Citation:

Cantú-Bernal $S$,

Domínguez-Gámez M,

Medina-Peraza I, Aros-Uzarraga E,

Ontiveros N, Flores-Mendoza L,

Gomez-Flores R, Tamez-Guerra $P$ and

González-Ochoa G (2020) Enhanced Viability and Anti-rotavirus Effect

of Bifidobacterium longum and Lactobacillus plantarum in Combination With Chlorella sorokiniana in a Dairy Product.

Front. Microbiol. 11:875 doi: 10.3389/fmicb.2020.00875

\section{Enhanced Viability and Anti-rotavirus Effect of Bifidobacterium longum and Lactobacillus plantarum in Combination With Chlorella sorokiniana in a Dairy Product}

\author{
Servando Cantú-Bernal'1, Maribel Domínguez-Gámez', Ivana Medina-Peraza², \\ Elizama Aros-Uzarraga ${ }^{2}$, Noé Ontiveros², Lilian Flores-Mendoza², \\ Ricardo Gomez-Flores ${ }^{1}$, Patricia Tamez-Guerra ${ }^{1}$ and Guadalupe González-Ochoa2* \\ 'Laboratorio de Inmunología y Virología, Departamento de Microbiología e Inmunología, Facultad de Ciencias Biológicas, \\ Universidad Autónoma de Nuevo León, San Nicolás de los Garza, Mexico, ${ }^{2}$ Laboratorio de Microbiología e Inmunología, \\ Departamento de Ciencias Químico Biológicas y Agropecuarias, Universidad de Sonora, Sonora, Mexico
}

Microalgae and probiotics such as Bifidobacterium and Lactobacillus genera are associated with human beneficial effects. The aim of this study was to evaluate the activity of Chlorella sorokiniana on Bifidobacterium longum and Lactobacillus plantarum viability in a dairy product (flan) and its microbial effect against rotavirus, which is one of the major diarrhea-causing pathogens worldwide. Microalge were isolated from a Mexican river and characterized by molecular tools. Their prebiotic activity was evaluated by determining Bifidobacterium longum and Lactobacillus plantarum shelf-life after incorporation in the food matrix. In addition, HT-29 cells were infected with rotavirus Wa and treated with $1 \times 10^{9} \mathrm{CFU} / \mathrm{mL}$ L. plantarum and B. longum metabolites alone or in combination with $1 \times 10^{9}$ cells/mL Chlorella sorokiniana; viral titers in probioticsand/or microalgae-treated cells were evaluated for antiviral activity. Results indicated that C. sorokiniana not only significantly $(p<0.05)$ improved $L$. plantarum and $B$. longum viability in flan, but also increased their antiviral activity; potent anti-rotavirus effect of C. sorokiniana alone was observed. Although more studies are needed, results suggest that incorporation of this microalga into a dairy product confers enhanced viability and antiviral effects, which indicates that $C$. sorokiniana might be used as an ingredient to design products with additional health benefits.

Keywords: microalga, probiotic, flan, shelf-life, metabolites, rotavirus

\section{INTRODUCTION}

The microalga Chlorella spp. is an important source of bioactive compounds such as proteins, fatty acids, carotenoids, sulfated polysaccharides, vitamins, and other natural bioactive molecules. This microalga is an important ingredient in functional foods because of its nutritional and pharmaceutical properties (de Morais et al., 2015; Silva et al., 2019). In addition, Chlorella spp. 
extracts have shown potential to modulate human immune response, accelerate dioxin elimination, prevent stress-induced ulcers, and decrease high-fat-diet-induced dyslipidemia (Ciliberti et al., 2019). Furthermore, microalga extracts incorporation into food triggers an array of metabolic and immunological processes in human and monogastric animal intestines stressed by enteric bacterial pathogens (Hulst et al., 2019). Notably, microalga sulfated polysaccharides have been associated with blocking viral entry to cells, thus avoiding infection (Guedes et al., 2011).

Probiotics are often used to prevent enteric diseases (SalesCampos et al., 2019) and decrease diarrhea severity, days with symptoms, and reinfections (Huang et al., 2002). Particularly, Bifidobacterium and Lactobacillus genera are the most commonly associated probiotics with beneficial effects for humans, mainly against enteric infections, such as the one caused by rotavirus (Gonzalez-Ochoa et al., 2017; Park et al., 2017). These probiotics and their metabolites modulate the cytokine milieu, stimulated by the gut-associated lymphoid tissue and improves intestinal barrier function against pathogens by promoting an efficient immune response (Vlasova et al., 2016; Tang and Lu, 2019).

Although probiotics have shown beneficial effects on human health, they are strain-, dose-, and viability-dependent. For instance, in probiotic fermented milks production, the viability of probiotics is lost during the fermentation process and storage at cold (refrigerator) conditions (Terpou et al., 2019). However, probiotics must be viable and abundant $\left(10^{6} \mathrm{CFU} / \mathrm{gr}\right)$ at the time of food product consumption to obtain the health benefits associated with these microorganisms (Terpou et al., 2019). Probiotics effectiveness would be improved by incorporating prebiotics into the food matrix; they produce compounds that stimulate probiotics growth and function (Beheshtipour et al., 2013). The aim of the present study was to evaluate the effect of $C$. sorokiniana to improve the viability of Bifidobacterium longum and Lactobacillus plantarum in a stored dairy food product and determine its antimicrobial effect against rotavirus, which is one of the main causing-diarrhea pathogens worldwide.

\section{MATERIALS AND METHODS}

\section{Probiotics}

The probiotics strains Lactobacillus plantarum (ATCC LP299v) and Bifidobacterium longum (ATCC 15707) were kindly provided by Porfiria Barrón from the Laboratorio de Biología Celular of Facultad de Ciencias Biológicas at Universidad Autónoma de Nuevo León, México. They were grown on MPT medium as previously described (MendozaFlores, 2014; González and Quiñones-Gutiérrez, 2018). This medium contains $2.5 \mathrm{~g}$ yeast extract, $0.50 \mathrm{~g}$ sodium chloride, $0.5 \mathrm{~g}$ L-cysteine hydrochloride, $0.05 \mathrm{~g}$ ascorbic acid, $0.25 \mathrm{~g}$ potassium phosphate dibasic, $0.15 \mathrm{~g}$ potassium phosphate monobasic, $0.124 \mathrm{mg}$ ferric ammonium citrate, $10 \mathrm{~g}$ casein digest peptone, and $5.0 \mathrm{~g}$ glucose (González and Quiñones-Gutiérrez, 2018). Microbial growth kinetics was determined by turbidimetry; once the exponential phase was identified, colony-forming units per milliliter $(\mathrm{CFU} / \mathrm{mL})$ were calculated by serial dilutions on agar plates and the bacterial inoculum was adjusted to $1 \times 10^{6}$ or $1 \times 10^{9} \mathrm{CFU} / \mathrm{mL}$, depending on the assay.

\section{Cells}

Human colon cancer (HT-29; ATCC ${ }^{\circledR} \mathrm{HTB}^{-38^{\mathrm{TM}}}$ ) and African green monkey kidney (MA104; ATCC ${ }^{\circledR}$ CRL-2378 ${ }^{\mathrm{TM}}$ ) cell lines were used in this study. They were grown in RPMI medium (Gibco/Life Technologies, Grand Island, NY, United States) supplemented with $5 \%$ of fetal bovine serum (FBS; Mediatech, Herndon, VA, United States), 2 mM L-glutamine, and 1\% antibiotic and antimycotic solution (Caisson Laboratories, North Logan, UT, United States), and incubated at $37^{\circ} \mathrm{C}$ in $5 \% \mathrm{CO}_{2}$, until confluence. Cells were then harvested using PBS and $0.25 \%$ trypsin (Mediatech, Herndon, VA, United States) at $37^{\circ} \mathrm{C}$, until detachment from the culture flask, and transferred to 6-well plates for probiotics, microalgae, and rotavirus assays or 96well plates for rotavirus microtitration. Probiotics and microalga cytotoxicity to HT-29 and MA014 cells was determined by the MTT reduction assay, as previously described (Mosmann, 1983).

\section{Rotavirus Strains}

The rotavirus strain Wa was kindly provided by Dra. Susana López from the Instituto de Biotecnología at Universidad Nacional Autónoma de México. Viral particles were propagated in MA104 cells and activated with $10 \mu \mathrm{g} / \mathrm{mL}$ of trypsin, incubated at $37^{\circ} \mathrm{C}$ in $5 \% \mathrm{CO}_{2}$ for $1 \mathrm{~h}$, the inoculum replaced by RPMI medium without $\mathrm{FBS}$, and incubated at $37^{\circ} \mathrm{C}$ in $5 \% \mathrm{CO}_{2}$, until cell lysis. Viral titers were calculated as focus forming units per milliliter $(\mathrm{FFU} / \mathrm{mL})$, using an immunochemistry assay protocol (Chasey, 1980). In brief, lysates from virus propagation or cells infected with rotavirus and treated with probiotics and the microalga were used to infect MA104 in 96-well plates; after $14 \mathrm{~h}$ of incubation, cells were fixed with a cold acetone-PBS solution and incubated for $45 \mathrm{~min}$ at room temperature. Monolayer was then washed twice with PBS, primary anti-rotavirus antibodies (Invitrogen, Carlsbad, CA, United States) were added, and cells incubated $1 \mathrm{~h}$ at $37^{\circ} \mathrm{C}$ and washed. Next, horseradish peroxidase (HRP)-anti-sheep IgG conjugate (Invitrogen, Carlsbad, CA, United States) was added to the cells and incubated $1 \mathrm{~h}$ at $37^{\circ} \mathrm{C}$, followed by the addition of the substrate aminoethylcarbazole (0.64 mg/mL; Sigma-Aldrich, St. Louis, MO, United States), prepared in dimethylformamide (Sigma-Aldrich) with acetate buffer (30 mM sodium acetate and $12 \mathrm{mM}$ acetic acid), $\mathrm{pH}$ 5.0, plus $0.36 \%$ hydrogen peroxide. Infected cells were counted using optical microscopy and identified by their brown color, indicating presence of viral antigens. FFU/mL were calculated using the following formula: $\mathrm{FFU} / \mathrm{mL}=20 \times($ microscope objective $) \times 5.5$ (well diameter) $\times$ average number of focus (duplicate, 100-200 focus count/well) $\times$ dilution (focus count). Rotavirus multiplicity of infection (MOI) was 0.01 in each assay.

\section{Microalgae Growth Conditions and Characterization}

Microalgae were isolated in the river San Juan Cadereyta in Nuevo León, Mexico (Reyna-Martinez et al., 2018). They 


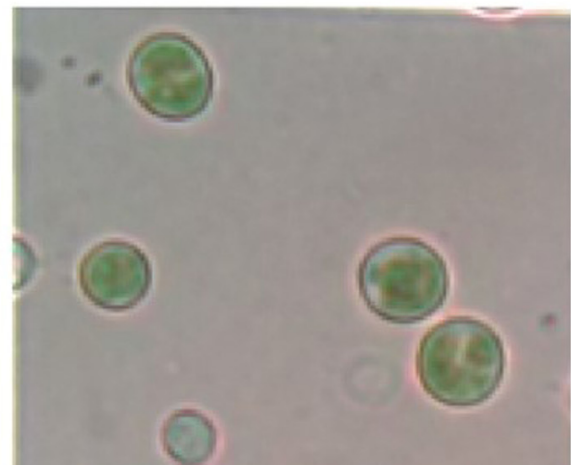

(a)

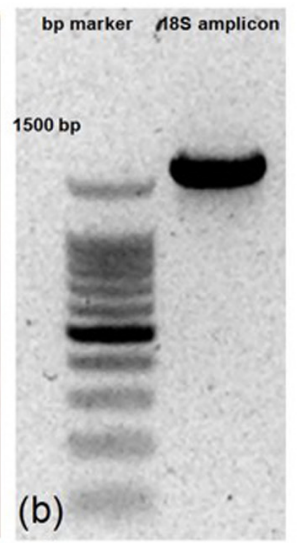

(c)

53

KR092112 Chlorella sorokiniana

KF444207 Chlorella sorokiniana

DI1340923 Chlorella vulgaris

KY921856 Chlorella sorokiniana

KP726220 Chlorella sorokiniana

KP726221 Chlorella sorokiniana

X62441 Chlorella sorokiniana

HQ111430 Chlorella pushelloides

KF864471 Chlorella sorokiniana

KF864476 Chlorella sorokiniana

X63504 Chlorella sorokiniana

KF661335 Chlorella vulgaris

KU900221 Tetradesmus obliquus

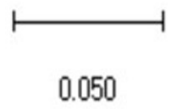

FIGURE 1 | Microalgae phenotypic and molecular characterization. (a) Microscopic characteristics of Ch/orella spp. (b) Partial amplification of Chlorella spp. 18S ribosomal RNA gene, (c) Phylogenetic analysis of $18 \mathrm{~S}$ ribosomal RNA amplicon which clustered with previously reported Chlorella sorokiniana sequences. The evolutionary history was inferred by using the Maximum Likelihood method and Tamura-Nei model. The tree is drawn to scale, with branch lengths measured in the number of substitutions per site. This analysis involved 18 nucleotide sequences. There were 1,596 positions in the final dataset. Evolutionary analyses were conducted in MEGA X (Kumar et al., 2018).

were grown in LC nutrient solution (5 $\mathrm{mM} \mathrm{KNO}_{3}, 1 \mathrm{mM}$ $\mathrm{KH}_{2} \mathrm{PO}_{4}, 2 \mathrm{mM} \mathrm{MgSO} 4 \cdot 7 \mathrm{H}_{2} \mathrm{O}, 6.25 \mathrm{mM} \mathrm{Ca}\left(\mathrm{NO}_{3}\right)_{2} \cdot 4 \mathrm{H}_{2} \mathrm{O}, 46$ $\mu \mathrm{M} \mathrm{H} \mathrm{HO}_{3}, 9.15 \mu \mathrm{M} \mathrm{MnCl} \cdot 4 \mathrm{H}_{2} \mathrm{O}, 765 \mathrm{nM} \mathrm{ZnSO}_{4} \cdot 7 \mathrm{H}_{2} \mathrm{O}$, $320 \mathrm{nM} \mathrm{CuSO} \cdot 5 \mathrm{H}_{2} \mathrm{O}, 15 \mathrm{nM}\left(\mathrm{NH}_{4}\right) 6 \mathrm{Mo}_{24} \mathrm{O}_{24} \cdot 4 \mathrm{H}_{2} \mathrm{O}, 20 \mu \mathrm{M}$ $\mathrm{FeSO}_{4} \cdot 7 \mathrm{H}_{2} \mathrm{O}$, and $20 \mu \mathrm{M} \mathrm{Na} \mathrm{EDTA}$ ) at $25^{\circ} \mathrm{C}$ and $120 \mathrm{rpm}$ with continuous light at 1,400 lumens for 12 days (López-Chuken

TABLE 1 | Proximate composition of Chlorella sorokiniana biomass.

\begin{tabular}{lc}
\hline Components & Content $\mathbf{~ m g / g}$ \\
\hline Protein & $307.7( \pm 24)$ \\
Carbohydrates & $225.3( \pm 28)$ \\
Lipids & $11.5( \pm 3.3)$ \\
Ash & $455.4( \pm 43)$ \\
Moisture & $122( \pm 6)$
\end{tabular}

et al., 2010). Microalgae were microscopically classified as the green microalga Chlorella spp. and was genetically classified by molecular tools as follows: $40 \mathrm{mg}$ of biomass in $1 \mathrm{~mL}$ of PBS were frozen with liquid nitrogen, homogenized at $8,000 \mathrm{rpm}$ for $1 \mathrm{~min}$, followed by DNA extraction, using the Purelink Genomic DNA kit (Invitrogen, Carlsbad, CA, United States). Purified DNA was used to amplify the $18 \mathrm{~S}$ ribosomal RNA gen, using the primers P2F 5'-GGCTCATTAAATCAGTTATAG-3'/P2R 5'-C CTTGTTACGA(C/T)TTCTCCTTC-3' (Lee and Hur, 2012). PCR amplicon (1700 bp) was purified with the Wizard SV Gel and PCR clean-up system Kit (Promega, Madison, WI, United States) and sequenced twice by the dideoxynucleotide chain termination method, using an ABI Prism BigDye terminator cycle sequencing ready reaction kit (Applied Biosystems, Foster City, CA, United States). The sequence of the isolated microalgae was submitted to the GenBank database with the access 
a

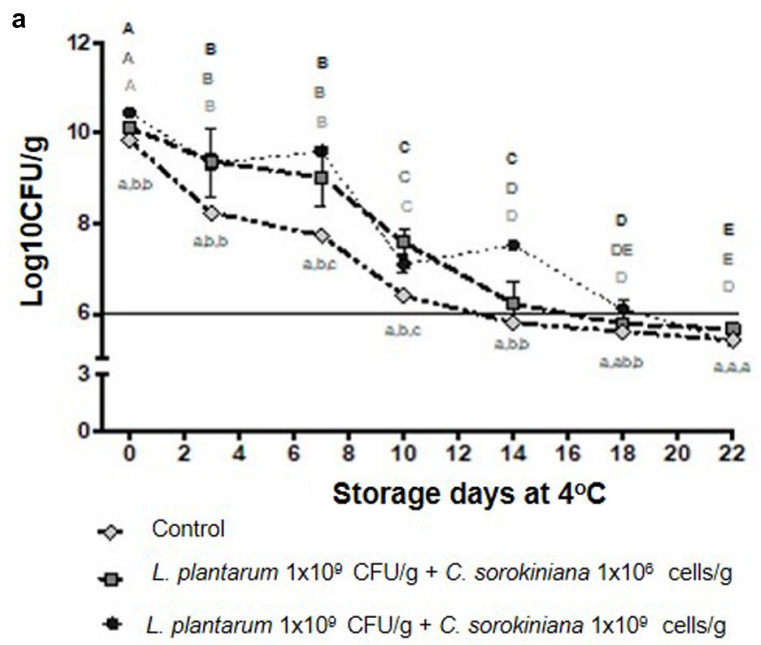

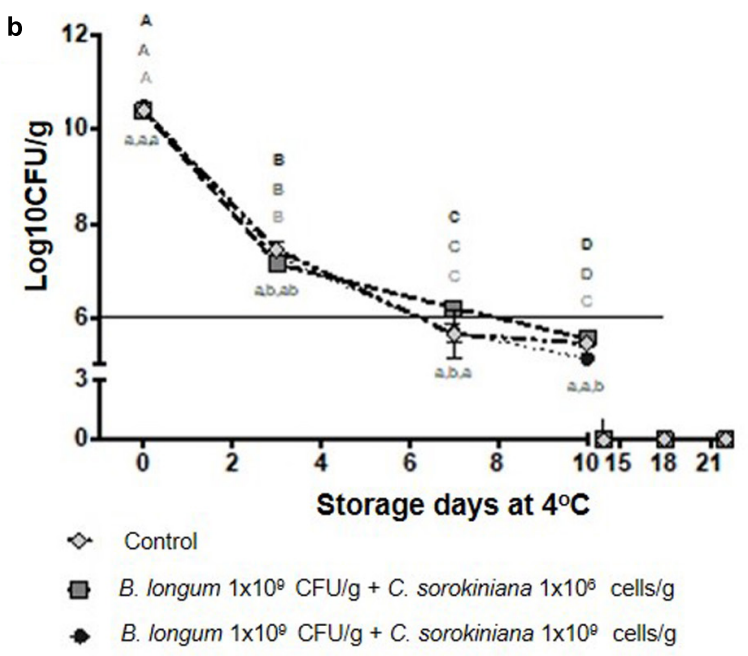

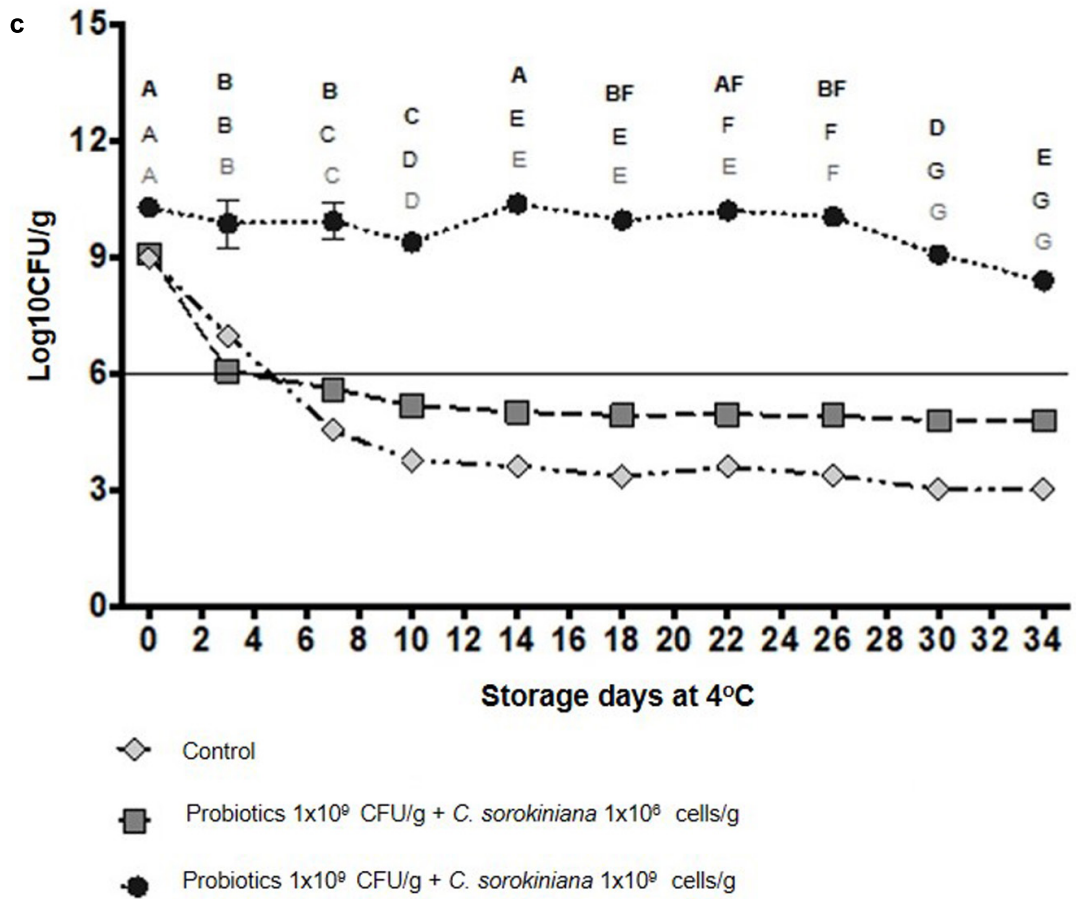

FIGURE 2 | Viability of Lactobacillus plantarum and Bifidobacterium longum in combination with Chlorella sorokiniana in a dairy product. (a) L. plantarum viability (days) alone and in combination with C. sorokiniana. (b) B. longum viability (days) alone and in combination with C. sorokiniana. (c) L. plantarum and B. longum viability (days) with and without $C$. sorokiniana. Lowercase letters indicate statistical significances between treatments at a specific time. Capital letters indicate statistical significances in treatment over time. Gray letters represent the control, black letters indicate L. plantarum or B. longum $\left(1 \times 10^{9} \mathrm{CFU} / \mathrm{g}\right)+$ C. sorokiniana $\left(1 \times 10^{6} \mathrm{Cells} / \mathrm{g}\right)$, and bold black represent $L$. planatrum or B. longum $\left(1 \times 10^{9} \mathrm{CFU} / \mathrm{g}\right)+\mathrm{C}$. sorokiniana $\left(1 \times 10^{9} \mathrm{Cells} / \mathrm{g}\right)$. Data were analyzed by two-way ANOVA with subsequent Fisher is LSD test using GraphPad Prism 7.0.

number MN011866. This was analyzed and compared with other sequences reported in GenBank database; phylogenetic relationships between strains were reconstructed using the maximum likelihood method with 1,000 replicates using MEGA X software (Kumar et al., 2018).

\section{Proximate Composition of Microalgae Biomass}

Association of Official Analytical Chemist (AOAC) methods were followed in detail. In brief, moisture was evaluated by drying the 
microalgae at $105^{\circ} \mathrm{C}$ for $24 \mathrm{~h}(\operatorname{method} 925.09 \mathrm{~B})$; crude protein was assessed using the micro-Kjeldahl assay (method 960.52); lipids were evaluated using a Soxhlet apparatus and petroleum ether as solvent (method 920.39C); ashes were calculated after incineration at $550^{\circ} \mathrm{C}$ (method 923.03), and carbohydrates by difference of the other components (AOAC, 1999). The results were expressed in $\mathrm{mg} / \mathrm{g}$ on a dry-matter basis. All evaluations were determined in triplicate.

\section{Probiotics and Microalgae Combination in a Dairy Product}

Combinations were made with probiotics at $1 \times 10^{9} \mathrm{CFU} / \mathrm{mL}$ and Chlorella spp. at $1 \times 10^{6}$ cells $/ \mathrm{mL}$ or $1 \times 10^{9}$ cells $/ \mathrm{mL}$ in $2 \mathrm{~g}$ of a dairy product such as flan and stored at $4^{\circ} \mathrm{C}$. Probiotics viability was monitored every 72 or 96 h of storage as follows: $1 \mathrm{~g}$ of flan containing the probiotic and/or microalgae was disrupted in PBS and diluted to calculate CFU/g. Microalgae were cultured independently from bacteria, thus, live microalgae were combined with probiotics. Assays were designed to take up to 34 days; nevertheless, results provided in figures indicated different treatment times, because experiments were ended once probiotic counts were lower than $10^{6} \mathrm{UFC} / \mathrm{gr}$.

\section{Probiotics and Microalgae Combination Against Rotavirus}

HT-29 cells were infected with rotavirus Wa (MOI 0.01), incubated $1 \mathrm{~h}$ at $37^{\circ} \mathrm{C}$ in $5 \% \quad \mathrm{CO}_{2}$, and treated with $2 \mathrm{~mL}$ of probiotic metabolites (Lactobacillus plantarum and/or Bifidobacterium longum at $1 \times 10^{9} \mathrm{CFU} / \mathrm{mL}$ ) and/or Chlorella sorokiniana $\left(1 \times 10^{9} \mathrm{CFU} / \mathrm{mL}\right)$ in $\mathrm{RPMI}$ medium without FBS, followed by incubation at $37^{\circ} \mathrm{C}$ in $5 \% \mathrm{CO}_{2}$ for $24 \mathrm{~h}$. After this, cells were stored at $-20^{\circ} \mathrm{C}$, until viral titration by immunochemistry.

\section{Statistical Analysis}

Data were reported as mean \pm SD of triplicate determinations from three independent experiments. Statistical analysis was determined by two-way ANOVA and Fisher's LSD multiple comparisons or Kruskal-Wallis and Dunn is multiple comparisons, using GraphPad Prism 7 (GraphPad Software Inc., San Diego, CA, United States).

\section{RESULTS}

\section{Phenotypic, Molecular, and Proximate Analyses of Microalgae}

Observed microalga characteristics indicated their correspondence with the genera Chlorella spp. (Figure 1a). The homologous sequence (99.7-100\%) of the $18 \mathrm{~S}$ ribosomal RNA gene (Figure 1b) and phylogenetic (Figure 1c) analyses revealed the presence of the green microalga Chlorella sorokiniana. Biomass analysis showed that this microalga was constituted on a dry-matter basis of $45.54 \%$ (455.4 mg/g) ash, $30.77 \%$ (307.7 $\mathrm{mg} / \mathrm{g}$ ) proteins, $1.15 \%(11.5 \mathrm{mg} / \mathrm{g})$ lipids, and $22.53 \%$ (225.3 mg/g) carbohydrates (Table $\mathbf{1})$.

\section{Incorporation of Chlorella sorokiniana Into a Dairy Product Increases Probiotics Viability}

The probiotics Lactobacillus plantarum and/or Bifidobacterium longum in combination with Chlorella sorokiniana were added to flan and stored at $4^{\circ} \mathrm{C}$ and probiotics viability evaluated every 72 or 96 h. L. plantarum and B. longum showed viability up to $1 \times 10^{6} \mathrm{CFU} / \mathrm{g}$ at 10 and 7 days, respectively, whereas addition of $C$. sorokiniana $\left(1 \times 10^{9}\right.$ cells $\left./ \mathrm{mL}\right)$ into the dairy product extended L. plantarum viability up to 18 days $(p<0.05)$ (Figure 2a); in contrast, it did not prolong that of $B$. longum (Figure 2b). On the other hand, L. plantarum, B. longum, and C. sorokiniana combination in flan showed longer viability $(>34$ days) than that of probiotic combinations without microalgae $(p<0.05)$ (Figure 2c).

\section{Probiotic Metabolites and C. sorokiniana Reduce Rotavirus Infectivity}

HT-29 cells were infected with rotavirus Wa (MOI 0.01) and treated with of L. plantarum and B. longum $\left(1 \times 10^{9}\right.$ $\mathrm{CFU} / \mathrm{mL}$ each) metabolites and/or C. sorokiniana $\left(1 \times 10^{9}\right.$ cells $/ \mathrm{mL}$ ). The microscopic cytopathic effect of rotavirusinfected cells treated with probiotic metabolites and C. sorokiniana was lower than that of infected cells without treatment. Lysates from metabolites-treated infected cells were used to evaluate the rotavirus viral titers $(\mathrm{FFU} / \mathrm{mL})$ in each assay (Figure 3). Rotavirus infectivity was reduced to 72,52 , and $64 \%$ after treatments with of B. longum and

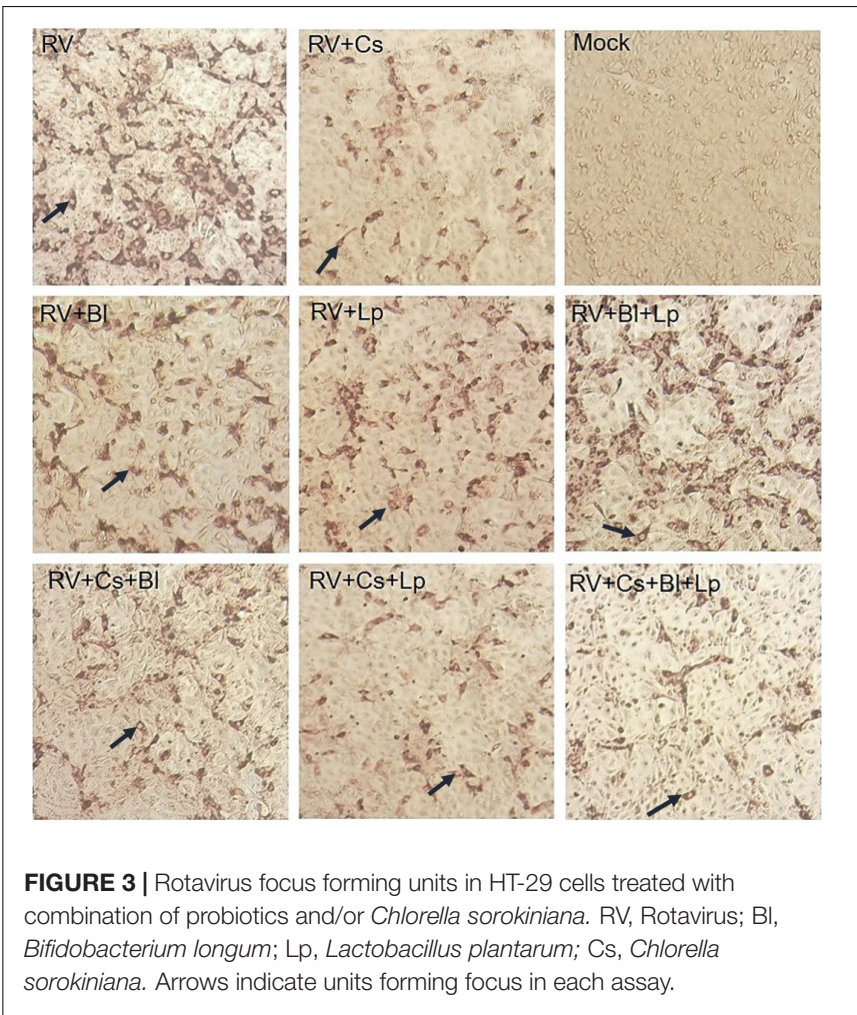




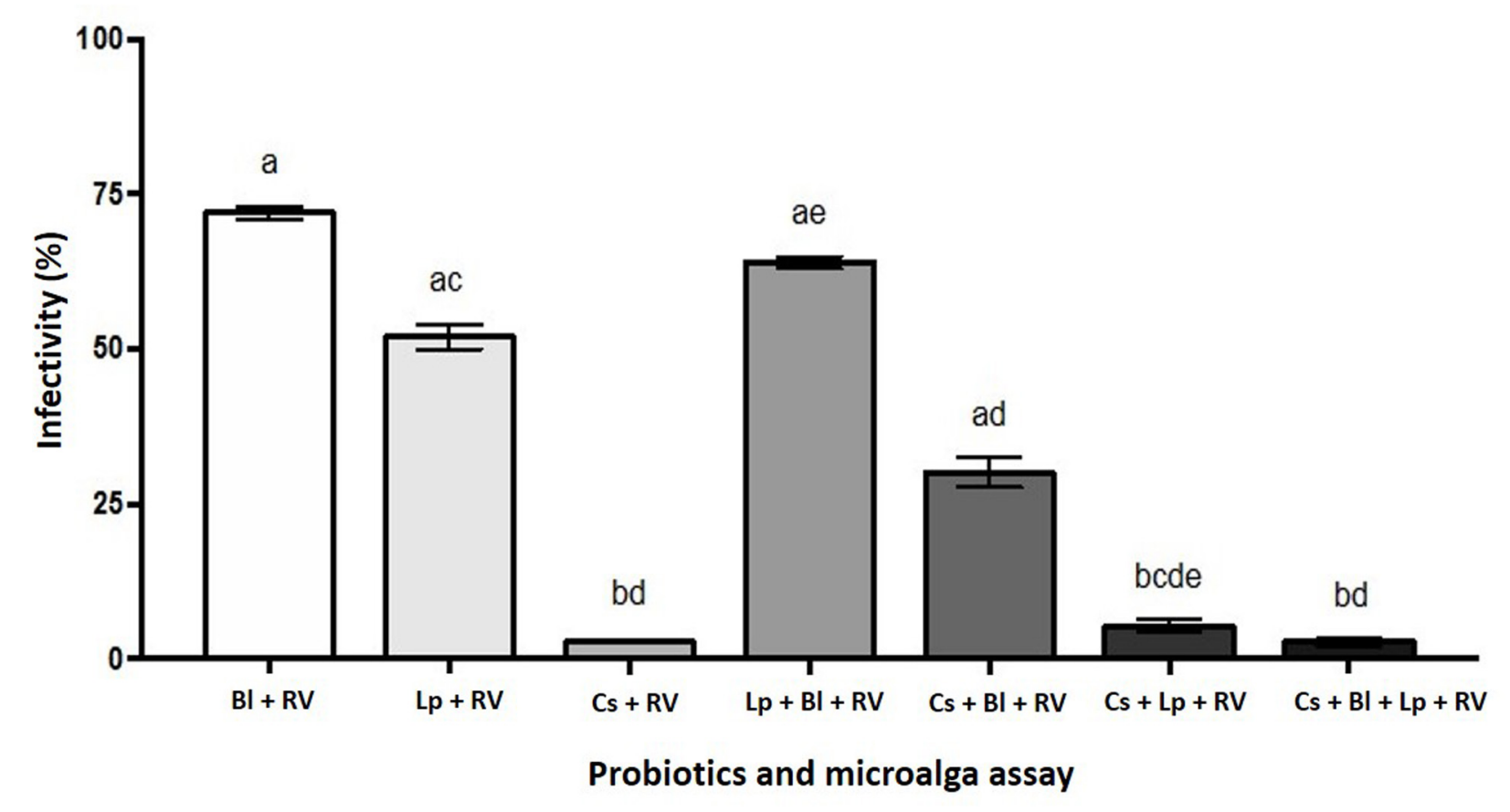

FIGURE $4 \mid$ B. longum, L. plantarum, and/or C. sorokiniana metabolites against rotavirus. Assays were performed in HT-29 cells, whereas viral titers were determined in MA104 cells. Viral titers of each assay were calculated as FFU/mL; viral infectivity percentage was estimated considering rotavirus titers in infected cells without any treatment as 100\% infectivity. RV, rotavirus; BI, Bifidobacterium longum; Lp, Lactobacillus plantarum; Cs, Chlorella sorokiniana. Different letters indicate statistical significances among treatments. Gray letters represent the control, black letters indicate probiotics $\left(1 \times 10^{9}\right)+C$. sorokiniana $\left(1 \times 10^{6}\right)$, and bold black represent probiotics $\left(1 \times 10^{9}\right)+$ C. sorokiniana $\left(1 \times 10^{9}\right)$, CFU/g. Data were analyzed by Kruskal-Wallis with subsequent Dunn's test using GraphPad Prism 7.0 .

L. plantarum metabolites alone or in combination, respectively (Figure 4). Each probiotic and combination significantly reduced rotavirus infectivity $(p<0.05)$, with no significant difference between the use of B. longum or L. plantarum. After adding C. sorokiniana metabolites to each treatment, infectivity was significant reduced to 30,8 , and $5 \%$, for B. longum, L. plantarum, or both probiotics, respectively (Figure 4). Notably, treatment with C. sorokiniana metabolites alone caused significant $(p<0.05) 4 \%$ reduction of rotavirus infectivity (Figure 4).

\section{DISCUSSION}

In this study, previously isolated microalgae were molecularly characterized by sequence homology and phylogeny of its $18 \mathrm{~S}$ ribosomal RNA gene (Reyna-Martinez et al., 2018). The sequence was clustered with other sequences previously reported as Chlorella sorokiniana (Figure 1c). This microalga species has been used for wastewater treatment, biodiesel production, and as a traditional dietary supplement due to its antitumoral, antibacterial, and antiviral activities (ReynaMartinez et al., 2018; Ciliberti et al., 2019; Hulst et al., 2019). The biochemical components of $C$. sorokiniana biomass grown under photoautotrophic conditions in our laboratory (Table 1), showed lower lipid, but higher protein, carbohydrate, and mineral levels than other microalgae such as Chlorella vulgaris cultured under photoautotrophic or mixotrophic conditions (Abreu et al., 2012; Dineshkumar et al., 2017).

In addition to $C$. sorokiniana characterization, its effect on probiotic viability was evaluated with $B$. longum and L. plantarum in flan (Figure 2). Among treatments, L. plantarum showed up and down numbers over time when supplemented with C. sorokiniana, both at $1 \times 10^{9}$ cells $/ \mathrm{mL}$ rate (Figure $2 \mathrm{a}$ ). This observation may be related to population secondary successions. In this regard, nutrition source availability should be responsible, since other physicochemical factors did not change during the experiment. The results indicated that this microalga improved L. plantarum viability alone or in combination with B. longum $(p<0.05)$ (Figure 2). In this regard, previous studies with C. sorokiniana and $C$. vulgaris also showed prebiotic activity by enhancing Lactobacillus rhamnosus growth; in addition, the prebiotic effect of $C$. sorokiniana was higher than that of C. vulgaris (Lai et al., 2019). Other genera of Chlorella have shown potential for improving $L$. acidophilus and B. lactis viability in yogurt (Beheshtipour et al., 2012, 2013). Although in the present study the mechanisms underlying the improved viability of probiotics after the addition of microalgae were not addressed, these could involve microalgae production of substances responsible for the stimulatory properties from a nutritional factor, such as adenine, hypoxanthine, and free amino acids (Varga et al., 2002; Gyenis et al., 2005; Beheshtipour et al., 2013). In this study, improved probiotics growth by $C$. sorokiniana was observed with metabolically active microalgae. Our results 
demonstrated that $C$. sorokiniana might be used as an ingredient in dairy food products in order to improve the probiotics such as B. longum and L. plantarum shelf-life. This study supports other reports describing the potential use of microalgae and blue-algae biomasses in milk-based functional fermented feeds (Varga et al., 2002; Gyenis et al., 2005; Beheshtipour et al., 2013). Although Chlorella is not yet formerly defined as prebiotic, it was recently considered as a functional food. Indeed, Chlorella used as feeding supplement in pigs have shown gastrointestinal effect in the manage of mild digestive disorders and in the fecal microbiota (increasing Lactobacillus concentration and reducing E. coli) (Yan et al., 2012; Furbeyre et al., 2017). Following in vitro digestion and fermentation, Chlorella was observed to increase propionate-producing microorganisms population in the intestines, which was associated with postbiotic gut health (Jin et al., 2020). Chlorella sorokiniana postbiotic effects represent one of our further research interests.

In addition to the increased viability of probiotics by Chlorella sorokiniana, other studies with this microalgae genus demonstrated its antibacterial activity against intestinal pathogens (Beheshtipour et al., 2012; Lai et al., 2019). In this study, B. longum and/or L. plantarum plus C. sorokiniana antiviral activity was evaluated in rotavirus-infected HT-29 cells (Figures 3, 4). Probiotics/microalga and cell metabolites showed potential to reduce rotavirus cytopathic effect, however, assays were performed using only metabolites due to interferences of probiotics/microalga cells with the immunochemistry stain of rotavirus-infected cells in viral titration. Results described in Figure 4 indicated that rotavirus titers decreased in cell cultures treated with B. longum or L. plantarum metabolites or after treatment with both probiotics' metabolites. Furthermore, the anti-rotavirus effect was improved after C. sorokiniana metabolites addition. Nevertheless, such improved anti-rotavirus effect cannot be fully attributed to the prebiotic properties of $C$. sorokiniana, since microalga metabolites showed a very potent antiviral effect per se, reducing rotavirus infectivity.

This study was designed to test the effect of C. sorokiniana on viability and antiviral activity of probiotics. Results showed an improved antiviral effect of probiotics, but unexpectedly, microalgae alone showed significant antiviral effect, which represents the first report on this matter to date. Recent reports showed C. sorokiniana effect against bacterial pathogens (Dineshkumar et al., 2017; Lai et al., 2019), whereas other microalgae species showed antiviral effects against murine cytomegalovirus (M-CMV) and herpes simplex virus type 1 (HSV-1) (Ibusuki and Minamishima, 1990; Shalaby, 2011; Santoyo et al., 2012). A recent study with C. sorokiniana demonstrated that the use of this microalga, before and after

\section{REFERENCES}

Abreu, A. P., Fernandes, B., Vicente, A. A., Teixeira, J., and Dragone, G. (2012). Mixotrophic cultivation of Chlorella vulgaris using industrial dairy waste as organic carbon source. Bioresour. Technol. 118, 61-66. doi: 10.1016/j.biortech. 2012.05.055 rotavirus infection in in vitro assays, increased type-I interferon expression levels, improving antiviral response and reducing the cytopathic rotavirus effect on HT-29 cells (Romero-Argüelles, 2020). Although Bifidobacterium spp. (Kim et al., 2014; Li et al., 2016; Olaya-Galan et al., 2016; Gonzalez-Ochoa et al., 2017) and Lactobacillus spp. (Ang et al., 2016; Olaya-Galan et al., 2016; Sunmola et al., 2019) antiviral effect, as well as the antimicrobial activity of Chlorella spp. have been documented, the present study showed that $C$. sorokiniana might be used as an ingredient in dairy food products to improve probiotics' viability and their effect against pathogens. As far as we know this is the first C. sorokiniana report demonstrating antiviral effect; although, more studies are needed to confirm C. sorokiniana specific effect against rotavirus.

\section{DATA AVAILABILITY STATEMENT}

The sequence of microalga Chlorella sorokiniana (18S ribosomal RNA gen partial gene) analyzed in this study can be found in the GenBank database with the access number MN011866 (https: //www.ncbi.nlm.nih.gov/nuccore/MN011866).

\section{AUTHOR CONTRIBUTIONS}

GG-O and PT-G conceived the study, designed, and supervised the experiments. SC-B and MD-G worked with the probiotics and microalga assays. IM-P, EA-U, and RG-F contributed with viral propagation and microtitration assays. NO contributed to growth experiments and biomass analysis. LF-M contributed in the sequence analysis and statistics. All the authors contributed to writing the manuscript, read, and approved the manuscript.

\section{FUNDING}

The research was supported by internal research support of the Universidad de Sonora projects USO513006130 and USO513005367 to GG-O.

\section{ACKNOWLEDGMENTS}

We wish to thank Consejo Nacional de Ciencia y Tecnología (Conacyt-Mexico) for scholarship 665130 to SC-B and 1989225 to MD-G; and to Sistema Nacional de Investigadores (SNIConacyt- Mexico) for supporting through SNI-16614 to PT-G, SNI-9942 to RG-F, SNI-77917 to NO, SNI-54907 to LF-M, and SNI-62977 to GG-O.

Ang, L. Y. E., Too, H. K. I., Tan, E. L., Chow, T.-K. V., Shek, P.-C. L., Tham, E., et al. (2016). Antiviral activity of Lactobacillus reuteri Protectis against Coxsackievirus A and Enterovirus 71 infection in human skeletal muscle and colon cell lines. Virol J. 13, 111-116. doi: 10.1186/s12985-016-0567-6

AOAC (1999). Official Methods of Analysis, 16th Edn. Washington, DC: Association of Official Analytical Chemists. 
Beheshtipour, H., Mortazavian, A., Haratian, P., and Darani, K. (2012). Effects of Chlorella vulgaris and Arthrospira platensis addition on viability of probiotic bacteria in yogurt and its biochemical properties. Eur Food Res Technol. 235, 719-728. doi: 10.1007/s00217-012-1843-3

Beheshtipour, H., Mortazavian, A., Mohammadi, R., Sohrabvandi, S., and Khosravi-Darani, K. (2013). Supplementation of Spirulina platensis and Chlorella vulgaris algae into probiotic fermented milks. Compr. Rev. Food Sci. 12, 144-156. doi: 10.1111/1541-4337.12004

Chasey, D. (1980). Investigation of immunoperoxidase-labelled rotavirus in tissue culture by light and electron microscopy. J. Gen. Virol. 50, 195-200. doi: 10. 1099/0022-1317-50-1-195

Ciliberti, M. G., Albenzio, M., Francavilla, M., Neglia, G., Esposito, L., and Caroprese, M. (2019). Extracts from microalga Chlorella sorokiniana exert an anti-proliferative effect and modulate cytokines in sheep peripheral blood mononuclear cells. Animals 9:45. doi: 10.3390/ani90 20045

de Morais, M. G., Vaz, B. D. S., de Morais, E. G., and Costa, J. A. V. (2015). Biologically active metabolites synthesized by microalgae. BioMed. Res. Int. 2015, 1-15. doi: 10.1155/2015/835761

Dineshkumar, R., Narendran, R., Jayasingam, P., and Sampathkumar, P. (2017). Cultivation and chemical composition of microalgae Chlorella vulgaris and its antibacterial activity against human pathogens. J. Aquac. Mar. Biol. 5:0019. doi: 10.15406/jamb.2017.05.00119

Furbeyre, H., Van Milgen, J., Mener, T., Gloaguen, M., and Labussiere, E. (2017). Effects of dietary supplementation with freshwater microalgae on growth performance, nutrient digestibility and gut health in weaned piglets. Animal 11, 183-192. doi: 10.1017/S1751731116 001543

González, M. B., and Quiñones-Gutiérrez, Y. (2018). Antibiosis of cefotaxime/clindamycin and Lactobacillus acidophilus on related bacteria to diabetic foot ulcer. Food Nutr. Sci. 9, 277-289. doi: 10.4236/fns.2018. 94022

Gonzalez-Ochoa, G., Flores-Mendoza, L. K., Icedo-Garcia, R., GomezFlores, R., and Tamez-Guerra, P. (2017). Modulation of rotavirus severe gastroenteritis by the combination of probiotics and prebiotics. Arch. Microbiol. 199, 953-961. doi: 10.1007/s00203-01 7-1400-3

Guedes, A. C., Amaro, H. M., and Malcata, F. X. (2011). Microalgae as sources of high added-value compounds-a brief review of recent work. Biotechnol. Prog. 27, 597-613. doi: 10.1002/btpr.575

Gyenis, B., Szigeti, J. F., Ásványi-Molnár, N., and Varga, L. (2005). Use of dried microalgal biomasses to stimulate acid production and growth of Lactobacillus plantarum and Enterococcus faecium in milk. Acta Agric. Kapos 9, 53-59.

Huang, J. S., Bousvaros, A., Lee, J. W., Diaz, A., and Davidson, E. J. (2002). Efficacy of probiotic use in acute diarrhea in children: a meta-analysis. Dig. Dis. Sci 47, 2625-2634.

Hulst, M., Van der Weide, R., Hoekman, A., and Van Krimpen, M. (2019). Transcriptional response of cultured porcine intestinal epithelial cells to micro algae extracts in the presence and absence of enterotoxigenic. Escherichia coli. Genes Nutr. 14, 8-23. doi: 10.1186/s12263-01 9-0632-z

Ibusuki, K., and Minamishima, Y. (1990). Effect of Chlorella vulgaris extracts on murine cytomegalovirus infections. Nat. Immun. Cell Growth Regul. 9, 121-128.

Jin, J. B., Cha, J. W., Shin, I. S., Jeon, J. Y., Cha, K. H., and Pan, C. H. (2020). Supplementation with Chlorella vulgaris, Chlorella protothecoides, and Schizochytrium sp. increases propionate producing bacteria in in vitro human gut fermentation. J. Sci. Food Agric. 100, 2938-2945. doi: 10.1002/jsfa. 10321

Kim, M. J., Lee, D. K., Park, J. E., Park, I. H., Seo, J. G., and Ha, N. J. (2014). Antiviral activity of Bifidobacterium adolescentis SPM1605 against Coxsackievirus B3. Biotechnol. Biotechnol. Equip. 28, 681-688. doi: 10.1080/13102818.2014. 945237

Kumar, S., Stecher, G., Li, M., Knyaz, C., and Tamura, K. (2018). MEGA X: molecular evolutionary genetics analysis across computing platforms. Mol. Biol. Evol. 35, 1547-1550. doi: 10.1093/molbev/ msy096
Lai, Y.-C., Chang, C.-H., Chen, C.-Y., Chang, J.-S., and Ng, I.-S. (2019). Towards protein production and application by using Chlorella species as circular economy. Bioresour. Technol. 289:12162. doi: 10.1016/j.biortech.2019. 121625

Lee, H.-J., and Hur, S.-B. (2012). Comparison between phylogenetic relationships based on $18 \mathrm{~S}$ rDNA sequences and growth by salinity of Chlorella-like species (Chlorophyta). Fish. Aquat. Sci. 15, 125-135. doi: 10.5657/FAS.2012. 0125

Li, D., Breiman, A., Le Pendu, J., and Uyttendaele, M. (2016). Anti-viral effect of Bifidobacterium adolescentis against Noroviruses. Front. Microbiol. 7:864. doi: 10.3389/fmicb.2016.00864

López-Chuken, U. J., Young, S. D., and Guzmán-Mar, J. L. (2010). Evaluating a 'biotic ligand model'applied to chloride-enhanced $\mathrm{Cd}$ uptake by Brassica juncea from nutrient solution at constant Cd2+ activity. Environ. Technol. 31, 307-318. doi: 10.1080/09593330903470685

Mendoza-Flores, P. (2014). Actividad Biológica de Factores Extracelulares de Lactobacillus casei, Lactobacillus Plantarum, Lactobacillus Acidophilus y Bifidobacterium Longum sobre la Línea Celular HT-29 de Cáncer de colon Humano. San Nicolás de los Garza, NL: Universidad Autónoma de Nuevo León.

Mosmann, T. (1983). Rapid colorimetric assay for cellular growth and survival: application to proliferation and cytotoxicity assays. J. Immunol. Methods 65, 55-63. doi: 10.1016/0022-1759(83) 90303-4

Olaya-Galan, N., Ulloa-Rubiano, J., Velez-Reyes, F., Fernandez-Duarte, K., SalasCardenas, S., and Gutierrez-Fernandez, M. (2016). In vitro antiviral activity of Lactobacillus casei and Bifidobacterium adolescentis against rotavirus infection monitored by NSP4 protein production. J. App. Microbiol. 120, 1041-1051. doi: 10.1111/jam.13069

Park, M., Kwon, B., Ku, S., and Ji, G. (2017). The efficacy of Bifidobacterium longum BORI and Lactobacillus acidophilus AD031 probiotic treatment in infants with rotavirus infection. Nutrients 9, 887-892. doi: 10.3390/nu90 80887

Reyna-Martinez, R., Gomez-Flores, R., López-Chuken, U., QuintanillaLicea, R., Caballero-Hernandez, D., Rodríguez-Padilla, C., et al. (2018). Antitumor activity of Chlorella sorokiniana and Scenedesmus sp. microalgae native of Nuevo León State. México. PeerJ. 6:e4358. doi: 10.7717/peerj. 4358

Romero-Argüelles, R. (2020). Efecto Antiviral de Bifidobacterium Longum y Chlorella Sorokiniana en un Modelo de Infeccioin in Vitro. San Nicolás de los Garza, NL: Universidad Autónoma de Nuevo León.

Sales-Campos, H., Soares, S. C., and Oliveira, C. J. F. (2019). An introduction of the role of probiotics in human infections and autoimmune diseases. Crit. Rev. Microbiol. 45, 413-432. doi: 10.1080/1040841X.2019.16 21261

Santoyo, S., Jaime, L., Plaza, M., Herrero, M., Rodriguez-Meizoso, I., Ibañez, E., et al. (2012). Antiviral compounds obtained from microalgae commonly used as carotenoid sources. J. Appl. Phycol. 24, 731-741. doi: 10.1007/s10811-0119692-1

Shalaby, E. (2011). Algae as promising organisms for environment and health. Plant Signal. Behav. 6, 1338-1350. doi: 10.4161/psb.6.9. 16779

Silva, J., Alves, C., Pinteus, S., Reboleira, J., Pedrosa, R., and Bernardino, S. (2019). Chlorella. In Nonvitamin and Nonmineral Nutritional Supplements. Cambridge, MA: Academic Press., 187-193.

Sunmola, A. A., Ogbole, O. O., Faleye, T. O., Adetoye, A., Adeniji, J. A., and Ayeni, F. A. (2019). Antiviral potentials of Lactobacillus plantarum, Lactobacillus amylovorus, and Enterococcus hirae against selected Enterovirus. Folia Microbiol. 64, 257-264. doi: 10.1007/s12223-01 8-0648-6

Tang, C., and Lu, Z. (2019). Health promoting activities of probiotics. J. Food Biochem. 43, e12944. doi: 10.1111/jfbc.12944

Terpou, A., Papadaki, A., Lappa, I. K., Kachrimanidou, V., Bosnea, L. A., and Kopsahelis, N. (2019). Probiotics in food systems: significance and emerging strategies towards improved viability and delivery of enhanced beneficial value. Nutrients 11, 1591-1623. doi: 10.3390/nu110 71591

Varga, L., Szigeti, J., Kovács, R., Földes, T., and Buti, S. (2002). Influence of a Spirulina platensis biomass on the microflora of fermented ABT milks during 
storage (R1). J. Dairy Sci. 85, 1031-1038. doi: 10.3168/jds.S0022-0302(02) 74163-5

Vlasova, A. N., Kandasamy, S., Chattha, K. S., Rajashekara, G., and Saif, L. J. (2016). Comparison of probiotic lactobacilli and bifidobacteria effects, immune responses and rotavirus vaccines and infection in different host species. Vet. Immunol. Immunopathol. 172, 72-84. doi: 10.1016/j.vetimm.2016. 01.003

Yan, L., Lim, S. U., and Kim, I. H. (2012). Effect of fermented Chlorella supplementation on growth performance, nutrient digestibility, blood characteristics, fecal microbial and fecal noxious gas content in growing pigs. Asian-Australas J Anim Sci. 25, 1742-1747. doi: 10.5713/ajas.2012. 12352
Conflict of Interest: The authors declare that the research was conducted in the absence of any commercial or financial relationships that could be construed as a potential conflict of interest.

Copyright () 2020 Cantú-Bernal, Domínguez-Gámez, Medina-Peraza, ArosUzarraga, Ontiveros, Flores-Mendoza, Gomez-Flores, Tamez-Guerra and GonzálezOchoa. This is an open-access article distributed under the terms of the Creative Commons Attribution License (CC BY). The use, distribution or reproduction in other forums is permitted, provided the original author(s) and the copyright owner(s) are credited and that the original publication in this journal is cited, in accordance with accepted academic practice. No use, distribution or reproduction is permitted which does not comply with these terms. 